\title{
Nucleolar Organiser Regions in Iris Melanocytic Tumours: An Accurate Predictor?
}

\author{
KIRSTIN DEUBLE* and ALISON McCARTNEY
}

London

\begin{abstract}
Summary
A silver staining technique which demonstrates the nucleolar organiser region (NOR) was used in paraffin sections of iris naevi and melanomas. The technique shows argyrophilic NOR associated proteins (AgNORs) which are seen in nuclei as black dots. In nine iris naevi the AgNOR count ranged from 1.54 to 3.82 (mean 2.73), in 21 melanomas from 1.89 to 8.31 (mean 4.67).

Mean AgNOR counts greater than four dots per nucleus were only seen in malignant lesions, thereby differentiating between benign and malignant tumours, whenever high AgNOR counts were found.

We subsequently examined three tumours in the intermediate group of aggressive naevi, Jakobiec group 6: there were counts averaging 4.08 but with a wide standard deviation of counts indicating that the behaviour of this group of aggressive tumours is likely to depend on the percentage of cells bearing the higher numbers of NORs, which may represent mitotic potential or increased metabolic rate.
\end{abstract}

Nucleolar organising regions are associated with the five acrocentric chromosomes (13,

\section{Nucleolar Organiser Region (NOR)}

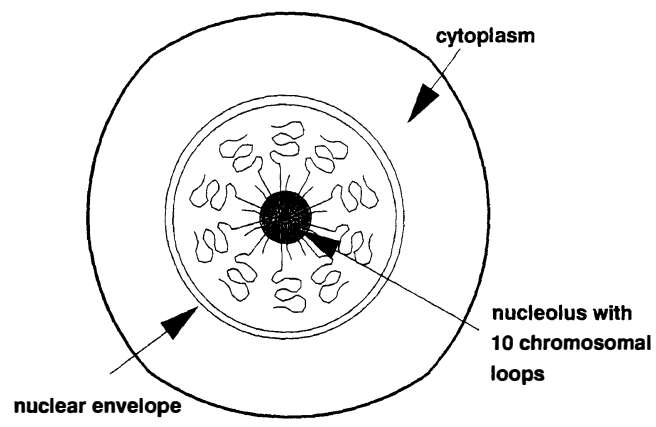

Fig. 1. Nucleolar organiser region with 10 chromosomal loops.
14, 15, 21 and 22) $)^{1}$ (Fig. 1) and have been shown by in situ hybridisation techniques to be loops of DNA that encode for ribosomal RNA. They appear as achromatic gaps on the short arms of the chromosomes examined in metaphase when banding techniques are used and in interphase studies they are shown to be present in the fibrillar centres and in the nucleolonemal dense fibrillary material. The deposition of silver in the AgNOR technique modified by Ploton and popularised by Crocker, ${ }^{2}$ is probably not on to NOR genes themselves but on to their associated proteins such as RNA polymerase I, by binding of sulphydryl groups (Fig. 2). This enzyme catalyses the transcription of ribosomal DNA to rRNA and has a molecular weight of $190 \mathrm{kD}$,

From: Department of Pathology, Institute of Ophthalmology, 17-25 Cayton Street, London EC1V 9AT.

*Current address: Allgemeines Krankenhaus Barmbek, Augenabteilung, Rübenkamp 148, 2000 Hamburg 60, West Germany.

Correspondence to: Dr A. C. E. McCartney, Department of Pathology, Institute of Ophthalmology, 17-25 Cayton Street, London EC1V 9AT. 


\section{Transcription of Ribosomes}

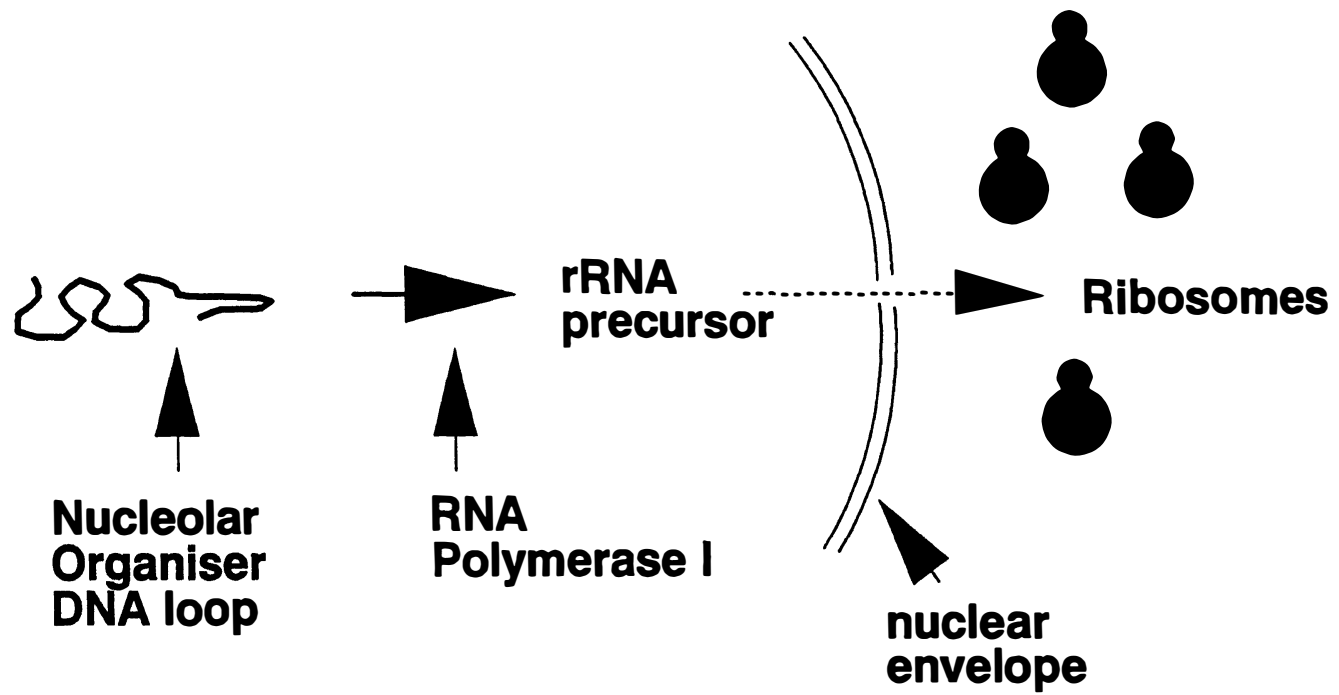

Fig. 2. Simplified diagram to show nucleolar organiser loops to transcribe ribosomes (modified from Crocker).

whilst other NORs of $110 \mathrm{kD}$ and $78 \mathrm{kD}$ have been detected in these regions.

Cytogeneticists have used these techniques since 1975 and were the first to observe that ectopic formation of NORs could occur in malignant cells, the initial observations being made on testicular tumours but other malignant cells were soon to follow. The transplantation of this sensitive research tool into the routine laboratory and into paraffin wax sections has largely been as a result of the efforts of Crocker and his team in Birmingham. They compared benign and malignant neoplastic and reactive conditions in lymph nodes, breast and most significantly for the ocular pathologist, in cutaneous melanocytic lesions, where naevi contained fewer AgNORs than melanomas, the naevi having a mean of 1.2 AgNORs per cell, whilst the melanomas, whether invasive or in situ had a mean of 7.9 AgNORs per cell. ${ }^{2}$

Initially it was thought that the numbers of AgNORs would only reflect the ploidy of the cells involved but sophisticated studies using flow cytometry, Ki67 immunoreactivity and other techniques have shown that AgNORs are more closely related to cell proliferation than to ploidy and these studies have been reinforced by work on interphase nuclei using cell kinetics. ${ }^{3}$

In histopathology, whilst it is interesting to be able to use a technique such as this to reinforce one's prejudices as to whether a given tumour is benign or malignant, the most potentially valuable observations are to be made on 'borderline' lesions of uncertain prognosis, whether in the ovary, colon or breast. For ocular pathologists, one of the most controversial tumours is the iris 'melanoma', which comprises $5 \%$ of intraocular melanocytic tumours. Jackobiec in his thought provoking paper of $1981^{4}$ suggested that most of the 189 iris melanocytic lesions on file at the Algernon Reese Laboratory were naevi and that $86 \%$ could be reassigned to this category based on their cytological bland nature. Some of these tumours recurred and some had aggressive characteristics including the evolution of a surface plaque that led to the development of intractable glaucoma but metastases were rare. His classification into nine categories pivots around the sixth group which he called borderline spindle $\mathrm{n}(\mathrm{a})$ evus. Most of these lesions had a surface plaque and small nucleoli were seen. Kersten et al..$^{5}$ disagreed with this viewpoint and felt that the good prognosis associated in all series of these tumours, of the order of $95 \%$ five year survival compared to $30 \%$ with choroidal melanoma, is due not to a quintessential benignity of iris melanocytic tumours but is a reflection of smaller bulk and earlier diagnosis. 
We decided to investigate the distribution of AgNOR counts in iris 'melanomas', partly to see if they followed the pattern of cutaneous melanocytic tumours in being divisible into benign or malignant on the basis of mean AgNOR numbers per cell and secondly to see if any prognostic significance can be attached to elevated counts. A previous collaborative investigation had established the distribution of AgNORs in choroidal melanomas and the results had been correlated with ploidy, tumour size and survival. ${ }^{6}$

We found that although malignant tumours could have low counts, something we had observed with the choroidal tumours, no benign tumour ever had a mean count of more than 4 AgNORs per cell. This was significant using parametric and nonparametric analysis. At the time of our original study ${ }^{7}$ we had not had the opportunity to study many of the aggressive naevi in the pivotal group but in this study we were able to include three such tumours and observed that locally elevated counts can be seen in some areas which are architecturally disquieting.

\section{Material and Methods}

Tissue We selected 33 countable iris lesions from the files of the Institute of Ophthalmology, where over 600 iris tumours and 6,000 choroidal melanomas are stored and compared the results to those of 56 choroidal melanomas previously selected for a joint project. $^{6}$

The iris lesions were initially classified using the Jakobiec classification which contains nine categories. ${ }^{4}$ These can be simplified into three:

\section{group 1-5 naevus}

group 6 aggressive naevus

group 7-9 malignant melanomà

The choroidal melanomas were similarly classified into:

group 7 spindle B cell melanoma

group 8 mixed tumour of spindle $B$ and epithelioid cell type

group 9 pure epithelioid melanoma.

Classification of the tumours was undertaken by three different observers, and only slides with an agreed diagnosis were taken for this study. The tissue (biopsies or enucleated eyes) had been fixed in $10 \%$ formalin and processed through to paraffin wax.
Of 41 iris lesions studied, only 30 were countable. Nine had been classified as naevi, 21 as iris melanomas. Three examples of aggressive naevi were also subsequently examined and the distribution of individual counts recorded.

Sixty-eight choroidal melanomas were processed but only 56 were countable.

Twenty-seven were spindle B cell melanomas, 28 mixed tumours, and one case was of a pure epithelioid cell type.

Uncountable tumours were tumours where heavy melanin deposits obscured the view and precluded accurate and repeatable counting. Bleaching the slides or using the Schmorl staining before silver staining was not helpful.

\section{Staining technique}

Sections were cut at $3 \mu \mathrm{m}$ thickness and were taken to water via xylene and graded ethanols. The sections were processed to demonstrate AgNORs at room temperature for 30 minutes. ${ }^{8}$ The reaction mixture comprised $2 \%$ gelatin in $1 \%$ aqueous formic acid. This was mixed in a proportion of $1: 2$ volumes with $50 \%$ aqueous silver nitrate under dark room conditions. After staining, the sections were exposed to xylene and mounted in synthetic medium.

\section{Counting procedure}

Sections were examined under an oil immersion lens with additional magnification provided by Optovar at a magnification of 2,000, and 100 nuclei were studied per slide.

\section{Results}

In the specimens AgNORs were visible as black dots of varying sizes in the nuclei (Figs. 3 and 4).

\section{Iris lesions}

In the nine iris naevi the AgNOR count ranged from 1.54 to 3.82 (mean 2.73), in the 21 iris melanomas from 1.89 to 8.31 (mean 4.67). The mean for the intermediate aggressive naevus group was 4.08 . The results for all groups are shown in a scattergram (Fig. 5).

It is interesting to note in the 30 original iris tumours that none of the benign lesions in (Jakobiec) groups 2-5 had a mean count greater than $4 \mathrm{AgNORs}$ per cell. Parametric 


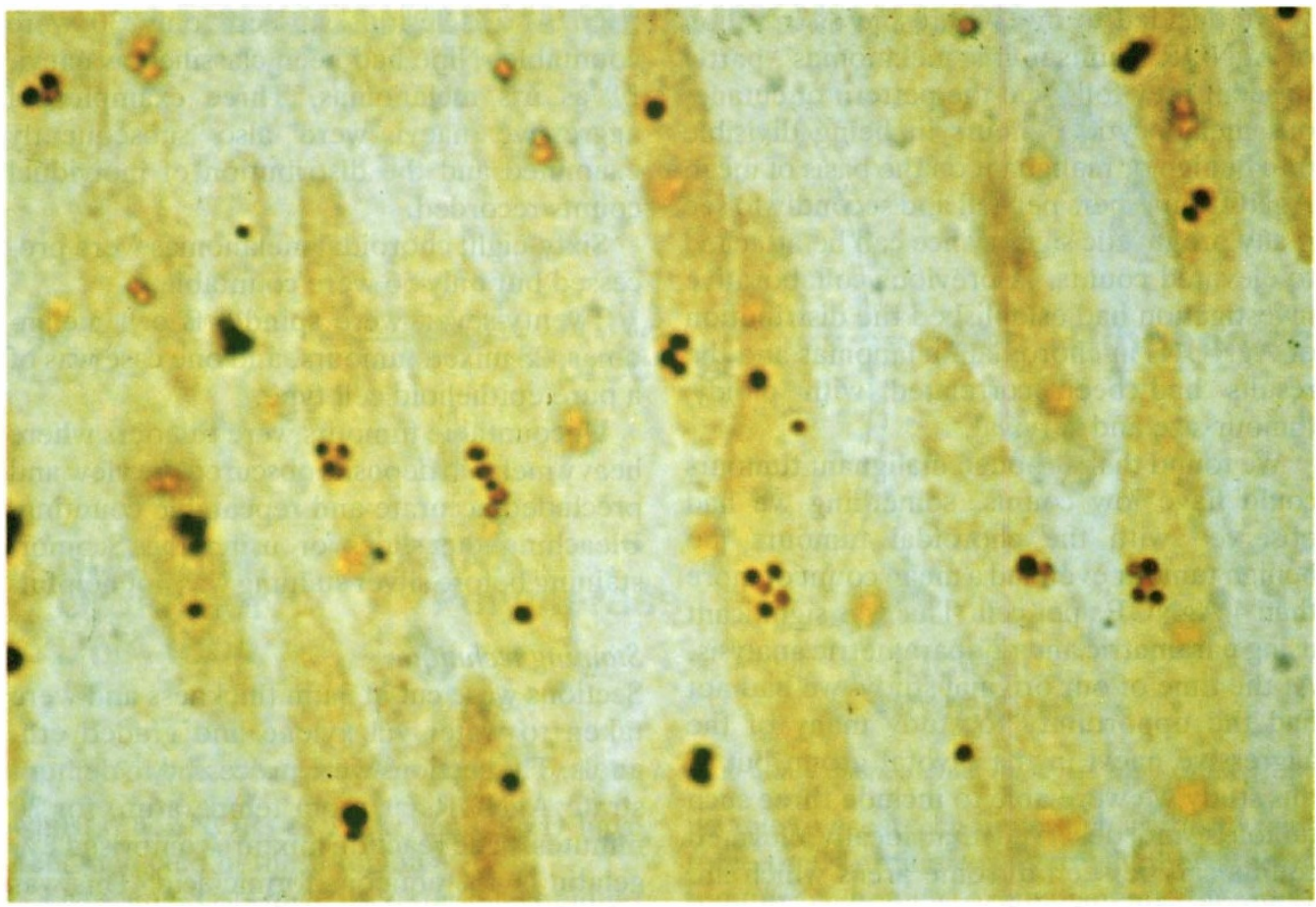

Fig. 3. AgNORs in an iris spindle cell melanoma. Original magnification $\times 640$.

and non-parametric statistics were used to show a significant difference between low grade and high grade iris tumours:

$$
\begin{array}{lll}
\text { Analysis of variance } & \mathrm{p}<0.0049 & \\
\text { Student's T-test } & \mathrm{p}=0.000466 & \\
\text { Mann Whitney rank } & \mathrm{p}=0.0005 & \\
\text { Kruskal-Wallis } & \mathrm{p}=0.05 & \text { for all groups } \\
& \mathrm{p}=0.001 & \begin{array}{l}
\text { for 2 groups } \\
\text { (benign/ }
\end{array} \\
& & \text { malignant) }
\end{array}
$$

In the intermediate group the mean counts were $3.95,4.06$ and 4.23 -figures that accurately reflect these tumours borderline histology and behaviour: a further analysis (Fig. 6) by histogram shows that there is considerable variation between cases and that case 1 in this category with counts of over ten AgNORs per cell might be expected to behave somewhat differently to the other two cases.

\section{Choroidal Melanomas}

The range for the AgNOR count in the malignant choroidal melanomas was 1.5 to 7.4 (mean 4.53). For the spindle cell type the mean AgNOR count was 4.45, for the mixed cell type it was 4.67. There were no significant differences between these two groups. The results for the 56 choroidal melanomas are shown in a scattergram (Fig. 7).

There was only one pure epithelioid malignant choroidal melanoma, with a mean count of 3.25 AgNORs per cell. This tumour was a most unusual case from a nine year old boy who has survived ten years without recurrence of his tumour.

\section{Discussion}

Although iris melanomas have an excellent prognosis when diagnosed and treated early, they still should not all be considered benign lesions. ${ }^{5}$ Jakobiec and Silbert found the longterm metastatic rate from iris melanomas to be of the order of $1 \%{ }^{4}$ but Kersten et al. thought that there had been an insufficiently longterm follow up ${ }^{5}$ and in a group of spindle cell lesions reported by Sunba et al.,${ }^{9}$ assignable to Jakobiec's group 7, four deaths occurred and in the epithelioid tumour (group 9) two deaths. These authors commented that the nucleoli were prominent in all seven tumours that caused death by metastases. In 


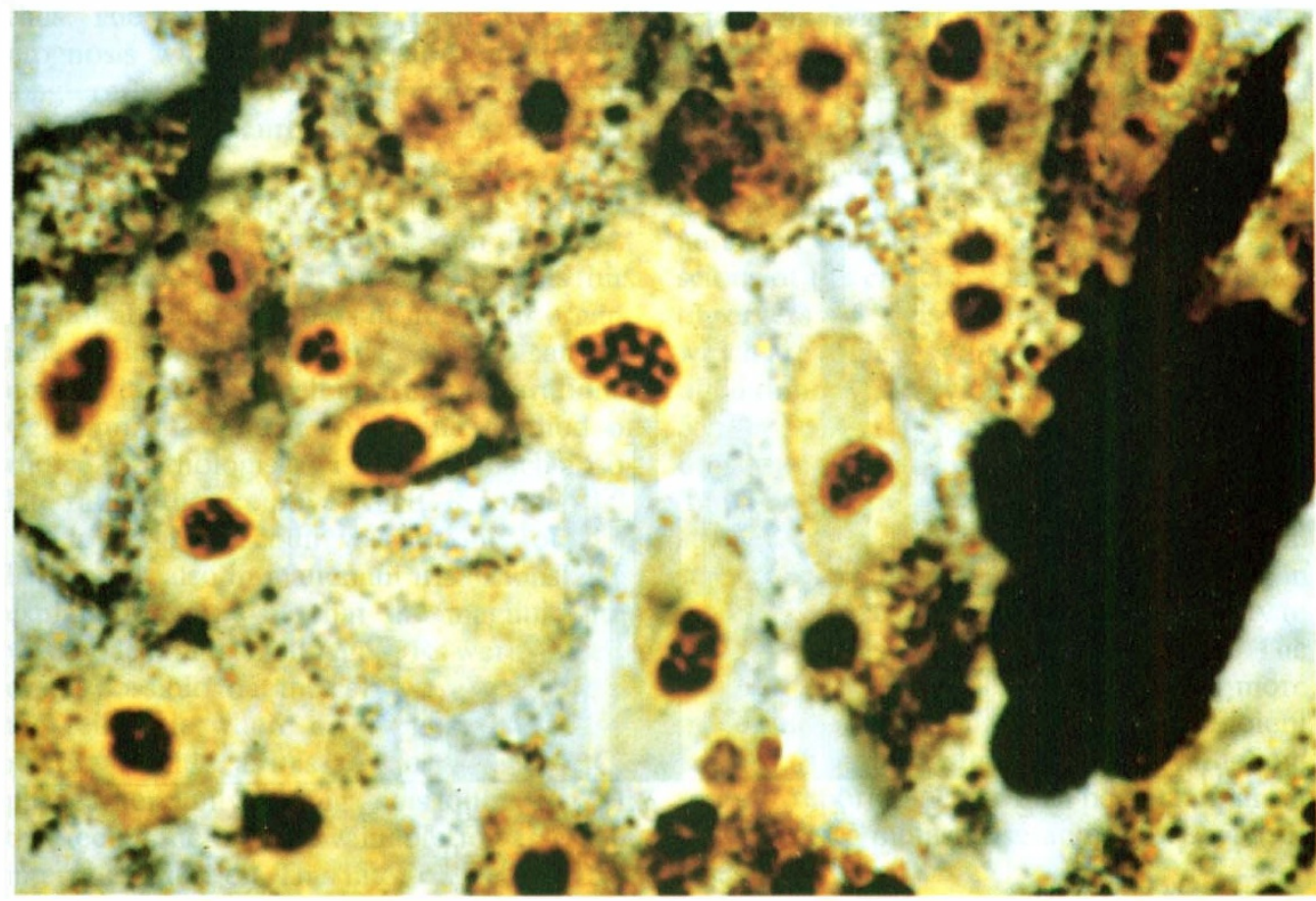

Fig. 4. High number of AgNORs in an iris epithelioid melanoma. Original magnification $\times 640$.

choroidal melanoma it has been established that the inverse standard deviation of the nucleolar area ISDNA and the number of epithelioid cells present per high power field are independent predictive factors using Cox proportional analysis. ${ }^{10}$ Estimation of ISDNA requires a computerised image analysis system and a motor driven microscope and is expensive.

Although the accurate histological diagnosis of iris lesions is often difficult, it is of vital importance in relation to compiling data on prognosis and therapy. Pathologists in various fields have used this argyrophilic technique to understand the behaviour of tumours and help in grading them. The simplicity of the AgNOR method, which is reproducible in different laboratories and interpreted with ease, together with its ready application to paraffin sections, makes it a potentially interesting method for the ocular histopathologist, even in retrospective studies.

After the initial observation that more nucleolar organiser regions were present in prostatic carcinoma cells than in cells from hyperplastic prostate, ${ }^{8}$ Crocker and Nar applied this technique to a large series of nonHodgkin's-lymphomas (NHL) and showed that the number of AgNOR dots within the nuclei was much greater in high-grade than in low-grade NHL. Other studies by the same researchers have shown the histological distinction between breast carcinoma and benign mammary lesions, benign and malignant pleural mesothelial cells, small cell bronchial carcinoma and lymphocytic infiltration, basal

AgNORs in melanocytic iris lesions

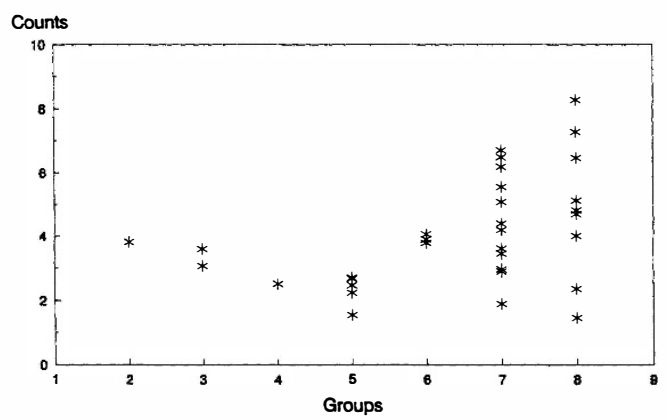

Fig. 5. Scattergram to show the AgNOR counts for 9 iris naevi (group 2-5), three intermediate group 6 and 21 iris melanomas (group 7-9). 


\section{AgNORs in aggressive iris naevi}

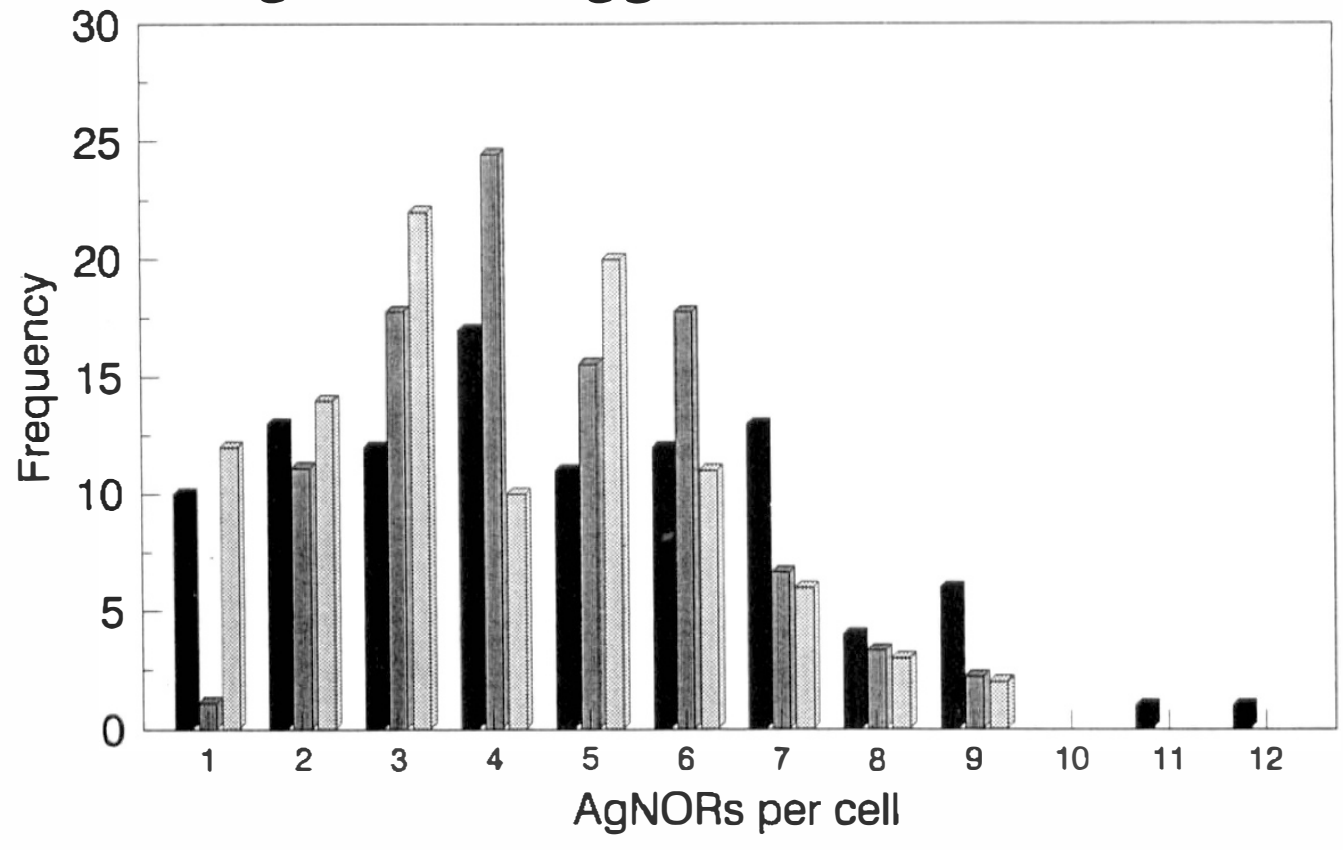

Case $1 \square$ Case $2 \square$ Case 3

Fig. 6. Histogram to illustrate variable frequency of AgNOR counts in group 6, aggressive iris naevi.

cell carcinoma and other basaloid tumours, ${ }^{11}$ and most importantly the clear differentiation between skin naevus and melanoma, ${ }^{2}$ which prompted this study. However, there are some studies where AgNOR counts have been less useful, for example in the differentiation between benign and malignant tissue of the thyroid, low-grade nonHodgkin's-lymphomas and normal lympho-

AgNORs in choroidal melanomas

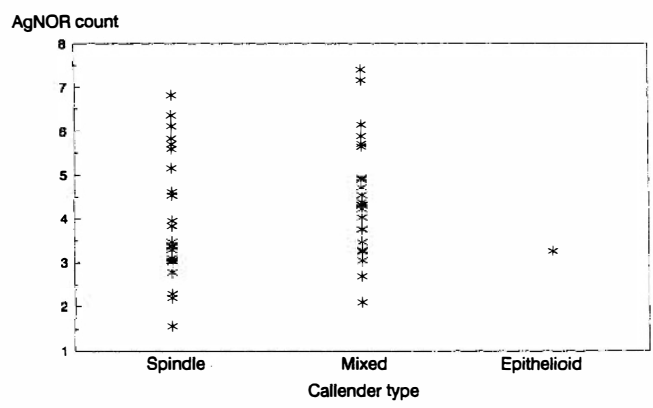

Fig. 7. Scattergram to show the AgNOR counts for 27 spindle $B$ cell type, 28 mixed cell type and 1 epithelioid cell type of choroidal melanoma. cytes, squamous cell carcinoma and benign skin tumours, recurrence and non-recurrence of meningiomas, and bronchial carcinoid tumours and small cell carcinoma of the bronNucleolar Organiser Regions

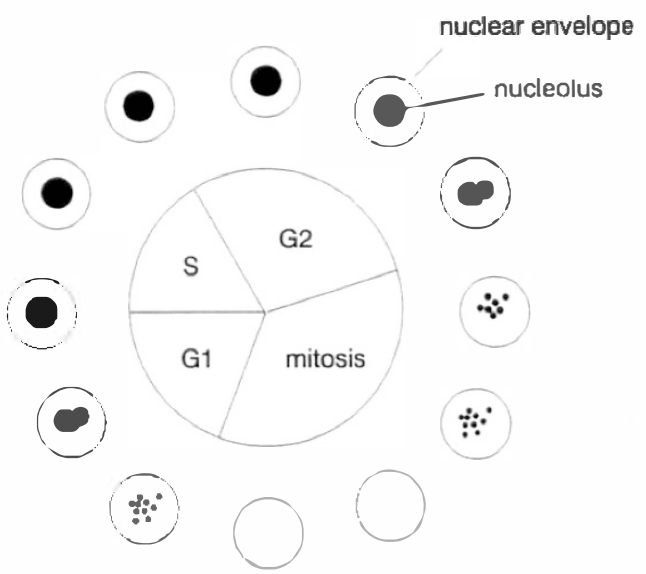

Fig. 8. Nucleolar organiser regions at different stages in the cell cycle (courtesy of Dr Seth Love). 
chus. The results particularly with regard to prognosis will have to be substantiated by longterm studies although some preliminary results on neuroblastoma are most encouraging. ${ }^{12}$

It has to be emphasised that the sections used in this study were cut at $3 \mu \mathrm{m}$ thickness, and the quoted numbers of AgNOR dots thus are not absolute numbers of nucleolar organiser regions per nucleus, which can be obtained only from cell imprint preparations. Cell imprints appear to be the method of choice if pathologists wish to approach absolute rather than relative AgNOR counts. ${ }^{13}$

A low AgNOR count was not only found in benign but also in malignant iris lesions. The explanation may be that the magnification was too low and small AgNORs were missed; or it is possible that the cells were in a stage in the cell cycle where no nucleolar organiser region is visible, as it is in mitosis, or S and G2 phase where only one big dot is found (Fig. 8); this technique is most valuable for assessing interphase nuclei. The inter-observer variation in counting which has been assessed as up to $5 \%{ }^{13}$ may account for the variation in the numbers of AgNORS counted in our two groups of tumours and the choroidal tumours reported $^{6}$ were counted at $\times 1000$ without the use of the Optovar. Nevertheless we believe that the considerable variation in the behaviour of this more overtly metastasising group of uveal melanomas may be explained by the AgNOR count once other known parameters affecting survival have been assessed and this data is currently undergoing Cox proportional hazard analysis and Kaplan-Meier curve fitting at Flinders University and will be reported separately.

The technique does seem to be useful in differentiating between benign and malignant tumours when a high count is found, but a low count may not necessarily be an indicator of benign behaviour. The figures relating to the intermediate group are most interesting with their variation around the cut-off point of four and the distribution of the counts (Fig. 6) illustrates considerable heterogeneity within this group of tumours. It was most interesting to observe that very high counts were often seen in those parts of the three tumours which appeared most vigorous and invasive and especially when tumours approached the angle, although the small numbers involved may make these observations tenuous. We are continuing clinicopathological surveillance of all patients studied and hope to report on the longterm follow up of these patients and their tumours in due course, being conscious of the criticisms levelled against other observers of these interesting iris lesions which are often less than half the size of choroidal tumours,${ }^{14}$ having an average volume of $55 \mathrm{~mm}^{3}$, a factor that may account for their otherwise puzzling or anomalous behaviour in 'failing' to metastasise. ${ }^{15} \mathrm{We}$ feel that our data supports the concept of continuous clonal selection within uveal melanomas resulting in heterogenous tumours with variable ability to invade aggressively and to metastasise. The fact that some large or cytologically more malignant tumours may behave in an indolent fashion, is illustrated by the epithelioid tumour reported here which had an apparent reluctance to metastasise and a low AgNOR count.

Dr Deuble was supported by the Deutsche Forschungsgemeinschaft (DFG) and the Royal Society.

The authors would like to acknowledge the help of Drs Brian Shine and Peter McCartney and that of Bipin Vaghela in the preparation of the manuscript.

References

${ }^{1}$ Editorial: NORS - a new method for the pathologist. Lancet 1987, 1: 1413-4.

${ }^{2}$ Crocker J and Skilbeck N: Nucleolar organiser region associated proteins in cutaneous melanotic lesions: a quantitative study. J Clin Pathol 1987, 40: 885-9.

${ }^{3}$ Hall PA and Levison DA: Review: Assessment of cell proliferation in histological material. J Clin Pathol 1990, 43: 184-92.

${ }^{4}$ Jakobiec FA and Silbert G: Are most iris 'melanomas' really nevi? Arch Ophthalmol 1981, 99: 2117-32.

${ }^{5}$ Kersten RC, Tse DT, Anderson R: Iris melanoma. Nevus or malignancy? Surv Ophthalmol 1985, 29: 423-33.

${ }^{6}$ Williams RA, Rode J, Charlton IG, Johns L, McCartney A: DNA content and nucleolar organising regions in ocular melanoma. J Pathol 1988, 156: 342A.

${ }^{7}$ Deuble K, McCartney A, Lightman S: Iris melanomas and malignancy. Proc Int Symp Tumours of the Eye. Essen 1989 (in press).

${ }^{8}$ Ploton D, Menager M, Jeannesson P, Himber G, Pigeon F, Adnet JJ: Improvement in the staining and in the visualization of the argyrophilic proteins of the nucleolar organiser region at the optical level. Histochem J 1986, 18: 5-14. 
${ }^{9}$ Sunba NMS, Rahi AHS, Morgan G: Tumours of the anterior uvea I. Metastasing malignant melanoma of the iris. Arch Ophthalmol 1980, 98: 82-5.

${ }^{10}$ Seddon JM, Poliviogianis L, Hsieh CC, Albert DM, Gamel JW, Gragoudas ES: Death from uveal melanoma. Number of epithelioid cells and inverse SD of nucleolar area as prognostic factors. Arch Ophthalmol 1987, 105: 801-6.

${ }^{11}$ Crocker J: Nucleolar organiser regions. In Underwood JCE ed Current topics in pathology; Nuclear pathology. Berlin: Spring-er-Verlag, 1989.
${ }^{12}$ Egan M, Raafat F, Crocker J, Williams D: Comparative study of the degree of differentiation of neuroblastoma and mean numbers of nucleolar organiser regions. J Clin Pathol 1988, 41: 527-31.

${ }^{13}$ Boldy DAR, Crocker J, Ayres JG: Application of the AgNOR method to cell imprints of lymphoid tissue. J Pathol 1989, 157: 75-9.

${ }^{14}$ Margo CE and Groden LR: Iris melanoma with extensive corneal invasion and metastases. $A m \mathrm{~J}$ Ophthalmol 1987, 104: 543-4.

${ }^{15}$ Editorial: Melanoma of the iris. Br J Ophthalmol 1989, 73: 586. 